\title{
MECHATRONIC SYSTEM FOR THE PROMOTION OF PHYSICAL ACTIVITY IN PEOPLE WITH MOTOR LIMITATIONS
}

\author{
Leandro Pereira ${ }^{1}$, José Machado ${ }^{2}$, Vítor Carvalho ${ }^{3}$, Filomena Soares ${ }^{4}$, Demétrio Matos ${ }^{5}$ \\ ${ }_{1}^{1}$ Mechanical Engineering Department, University of Minho, Campus de Azurem, Guimarães, Portugal, \\ ${ }^{2}$ MEtRICs Research Centre, University of Minho, Campus de Azurem, Guimarães, Portugal, \\ ${ }^{3} 2 \mathrm{Ai}$ Lab-IPCA-EST, Campus do IPCA, Barcelos, Portugal, \\ ${ }^{4}$ Algoritmi Research Centre, Industrial Electronics Department, University of Minho, Campus de Azurem, \\ Guimarães, Portugal, \\ ${ }^{5}$ ID+ - IPCA-ESD, Campus do IPCA, Barcelos, Portugal \\ a75901@alunos.uminho.pt, jmachado@dem.uminho.pt, vcarvalho@ipca.pt, \\ fsoares@dei.uminho.pt,dmatos@ipca.pt
}

\begin{abstract}
This work presents the initial step of the development of a mechatronic system that aims to promote physical activity in people with motor limitations. This mechatronic system consists of a stationary bike similar to the current gym bikes, with the difference of having a didactic component. The didactic component presents the integration of a game that simulates a paramotor in which the speed of pedalling allows the player to move up and down, while the position of the arms will allow the movement to the left and to the right in the game scenario. The model under study also presents the versatility of being able to ergonomically adjust to any person and to adjust the load for both upper and lower limbs. In this paper it is also detailed some aspects of the mechatronic system design, such as: modelling, study of materials and sensors, study of possible exercises, to be performed, and the development of the game scenario.
\end{abstract}

Keywords: Mechatronic Systems Design, Rehabilitation, Serious Game.

\section{Introduction}

Demographic trends, whether in developed countries or even in less developed countries, point to a sharp increase in the number of elderly people, many of them with motor problems. In Portugal, according to the Portuguese census of 2011, the percentage of young people decreased from $16 \%$ to $15 \%$ between 2001 and 2011, while the elderly population increased from $16 \%$ to $19 \%$. Consequently, the Portuguese aging index increased from 102 to 128 between 2001 and 2011 (INE, 2012) [1]. Aging and chronic diseases such as obesity, Parkinson's, hypertension, arthritis, diabetes and even symptoms resulting from strokes are the main factors that force people to gradually abandon their autonomy, making it more difficult to performing daily tasks such as bathing, dressing and walking. As many of the above diseases require rehabilitation, some researchers believe that active games (games involving physical activity) can increase adherence to treatment [2].

Several studies have shown that serious games have enormous potential in health intervention, including rehabilitation and physiotherapy. The pleasant atmosphere they create, and the feedback forms included, promote the interests of patients, who are increasingly motivated and involved in their rehabilitation [3]. Over the years several games have been developed with the purpose of promoting and improving the physical condition of the population in an effective and pleasant way. One of the first games of this genre was Foot Craz in 1987 and since then several games have been released, however the device that more success had was the popular Wii console of Nintendo [4]. In order to achieve the main goals of this paper, it is divided in eight sections as follows: the state of the art presents some devices that are currently used for the physical activity in an iterative way. The 3D modelling section presents the system under study as well as its modules and systems. In section selection of materials, it is made a study of the materials to be selected for the various parts of the model. In the following section it is presented an analysis to the sensors that will be part of the model making the acquisition of the inputs of the user. Then, the exercises that can be performed in the proposed model are presented in order to allow physical activity and rehabilitation. In the section development of the game scenario is presented the initial stage of the development of the game scenario, and, finally, some final remarks are presented. 


\section{State of the Art}

In table 1 is presented some equipment currently used for the promotion of physical activity and rehabilitation in an iterative and pleasant way.

By analysing the devices in the table above it can be verified the existence of several strengths in each of these systems, some of their strengths can be considered quite important for their acceptability and success, such as: adjustability to different people, versatility of training, dimensions, among others. Despite the great variety of interactive equipment that motivates people to exercise, it can be verified by the analysis of the table and equipment studied, that there is a need to create equipment of the same gender, but with a greater level of comfort and safety, so they can be used by people with motor limitations in a more pleasant and safe way [4].

Table 1. Equipment currently used for the promotion of physical activity and rehabilitation

\begin{tabular}{|c|c|}
\hline Device & Description \\
\hline ReaKing & $\begin{array}{l}\text { RanKinG is a serious virtual reality game that aims at the physical } \\
\text { rehabilitation of people with mobility problems through the use of a Kinect } \\
\text { camera [5]. This game is adjustable, transportable and compact, but it does } \\
\text { not provide great comfort and safety }\end{array}$ \\
\hline Physioland & $\begin{array}{l}\text { Physioland presents a serious game developed with the objective of allowing } \\
\text { physical therapy using a Kinect camera. The overall architecture of the game } \\
\text { is based on five main components: the game, the hardware, the peripherals, } \\
\text { the database and the player [6]. The Physioland is adjustable and has a } \\
\text { structure that allows to assist the patient in the execution of movements, } \\
\text { however the use of this structure requires some space for its installation. }\end{array}$ \\
\hline Smartfloor & $\begin{array}{l}\text { Smartfloor is a platform game that is designed to combat childhood obesity. It } \\
\text { was designed in a modular way, having } 36 \text { square panels of wood with load } \\
\text { cells in each of its } 4 \text { corners [7]. This system is adjustable, transportable and } \\
\text { compact, but it does not provide great comfort and safety to be used by people } \\
\text { withmotor limitations. }\end{array}$ \\
\hline Physiosensing & $\begin{array}{l}\text { PhysioSensing is a pressure platform for physiotherapy and rehabilitation } \\
\text { activities that has several functionalities, including: balance/stability, load } \\
\text { transfer, pressure mapping and therapeutic games [8]. This equipment is } \\
\text { compact and allows a wide variety of training, however, if the patient has } \\
\text { motor limitations it will be necessary a person to help. }\end{array}$ \\
\hline Twall & $\begin{array}{l}\text { Twall features an interactive wall that uses pulses of light to generate motion } \\
\text { sequences specifically[9]. This system aims at physical and iterative training, } \\
\text { allowing even group training, so it is not very suitable for people with motor } \\
\text { limitations. }\end{array}$ \\
\hline GymTop USB & $\begin{array}{l}\text { The Gym Top USB is a board with visual biofeedback technology, which can be } \\
\text { used for balance training, diagnosis of anatomical problems, resistance } \\
\text { training and bodybuilding of the legs and torso [10]. This system is adjustable } \\
\text { and compact, can be used in any computer and allows a good diversity of } \\
\text { exercises and diagnoses, however, The Gym Top USB does not have a great } \\
\text { level of comfort to be used by people with motor limitations, like most of the } \\
\text { equipment's presented in this table. }\end{array}$ \\
\hline BOBO Balance & $\begin{array}{l}\text { The BOBO Balance is a training board that converts traditional balance } \\
\text { devices into interactive training platforms. This technology aims to increase } \\
\text { patient involvement, enabling specific measurements [11]. This equipment } \\
\text { can be used in a training and rehabilitation situation, however in the case of } \\
\text { people with motor limitations it will be necessary a person to help in } \\
\text { performing the exercises }\end{array}$ \\
\hline Trixter VR & $\begin{array}{l}\text { This stationary bike offers a vast array of virtual realities, where it is possible } \\
\text { to hold local and even international competitions [12]. This equipment is } \\
\text { adjustable, versatile and allows the use of virtual reality glasses, however, it } \\
\text { has the disadvantage of not being very ergonomic because it simulates a real } \\
\text { bicycle. }\end{array}$ \\
\hline
\end{tabular}




\section{Modeling of the Proposed System}

The proposed 3D model presented on figure 1 resulted from an iterative process in which it was intended to choose the appropriated systems and to promote the desired versatility and functionality to the model. It was intended that this 3D model presented an equipment that: occupied the minimum space as possible; had a chair with adjustment capability; allowed to adjust the loads for different workouts and to provide the necessary comfort and safety to be used by people with motor limitations.

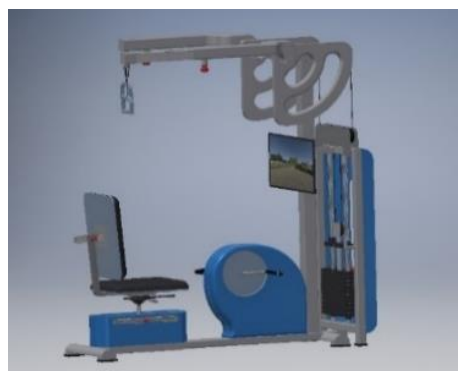

Figure 1: Proposed solution (3D model)

To occupy the smallest space possible a modular system was chosen. In this way it will be easier to reduce the space occupied by the model when it is fully assembled. Thus, it was decided to divide the model into 3 modules (chair module, pedal module and main module) presented below. This division into modules, besides allowing the disassembly and division of the equipment, will allow the adaptation to any chair, even allowing the use of wheelchairs [4].

\subsection{Chair Module}

This module was the one that went through more iterative processes since it required versatility. It was intended that this module would have the following adjustment capabilities: rotary adjustment, height adjustment, pedal distance adjustment and adjustment of the backrest. In addition, this module would also aim to provide the necessary comfort and safety, so it can be used by people with motor limitations. In figure 2 are presented the chair module.

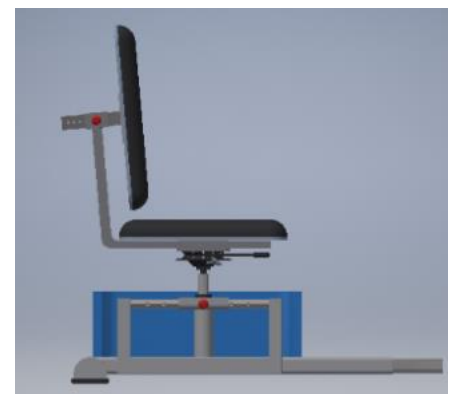

Figure 2: Chair module
The backrest adjustment and the pedal adjustment are made by sliding between the parts of the chair and a selector pin that locks the desired position. The height adjustment is done thanks to a non-rotating pneumatic cylinder, which is embedded in the support that also allows the adjustment of the approach to the pedal. Finally, the rotation is provided with a locking swivel. Figure 3 shows the systems described.

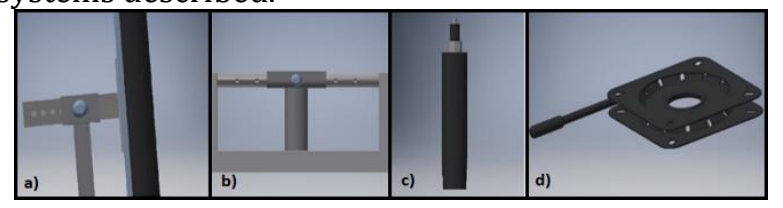

Figure 3: a) Backrest adjustment system;
b) Pedal adjustment system;
c) height adjustment system;
d) rotation adjustment system

\subsection{Pedal Module}

The pedal module presented on figure 4 features a common system and widely used on gym bikes. This system consists of the pulley-belt assembly in which the pedalling resistance is provided by a magnetic system.

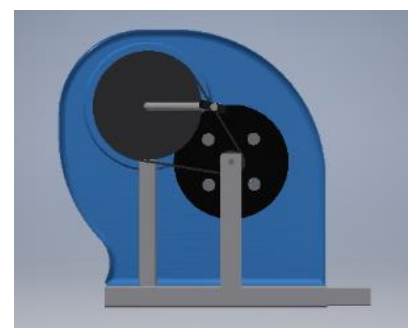

Figure 4: Pedal module

The operation of this magnetic system shown in figure 5 consists of the approach and removal of magnetic supports contained inside the flywheel through a stretcher. This module should also have a speed sensor that will be discussed later in the selection of the sensors chapter.

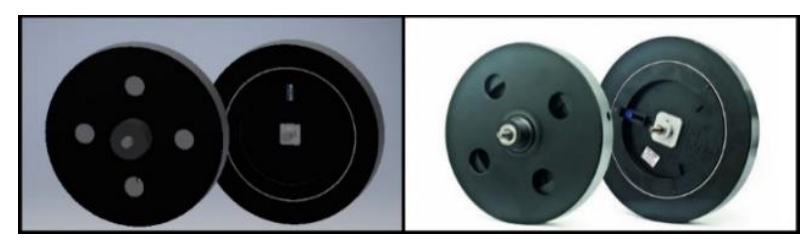

Figure 5: 3D modeling and actual component that will be used for pedal resistance [20].

\subsection{Main Module}

The main module shown in figure 6 presents all the necessary mechanisms for the execution of the arm movements required in the game. 


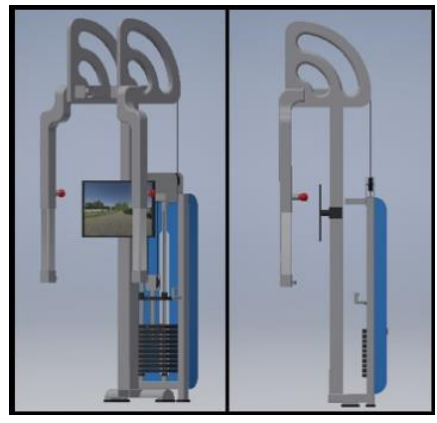

Figure 6: Peripheral view and side view of the main module

In this module the load can be selected according to the physical capacities of the user, to do this the player must select the weight he wants from a stack of weights that are connected to the system of pulleys shown in figure 7 . Besides the mechanisms necessary for the execution of the movements, this module also includes the game interface, and for this reason it is consider the main module. This module should also have a rotary position sensor (encoder) which will be further discussed in the selection of sensors section.

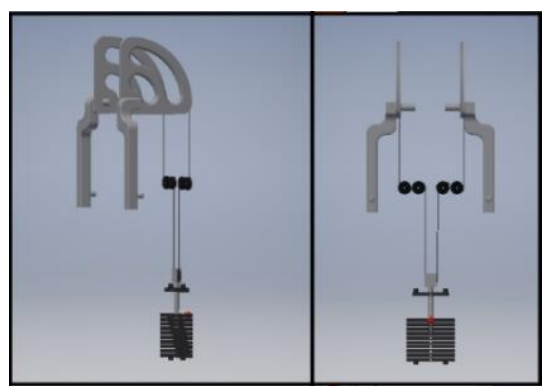

Figure 7: Peripheral view and rear view of the pulley system

\section{Selection of Materials}

Bicycles and gym equipment generally use some metallic materials, mostly carbon steels, chrome steels, cast irons, aluminium and stainless steels [13]. In this context, it can be verified that several materials may be used for manufacturing the structure of the system, however the most appropriate materials, that require study, are the steels, the aluminium alloys and the polymeric materials. For the design of the structure of the proposed system, it was decided to study steels from two distinct groups, which can respond to the required needs: carbon steels (widely used in mechanical engineering) and stainless steels (important for their resistance to phenomena of corrosion).

In [14] there are presented some characteristics of a general steel; in [15] it can be found a description of stainless steels.

Table 2 shows the comparison of the different studied steels. This comparison was made based on the relative weight attributed to each of the factors previously described (mechanical strength, density, corrosion resistance, ease of processing and cost). To better understand it, a score between 0 and 5 (where 0 means that the material does not have any properties relative to the factor to which it is being evaluated and 5 means that the material has good properties relative to the factor to which it is being evaluated) was assigned to each steel for the different factors, then it was multiplied the score attributed by the relative weight of the factor and finally it was made the sum of the multiplied values in each factor.

Table 2. Comparison and selection of the materials for the structure of the model

\begin{tabular}{|l|c|c|c|c|c|c|c|c|c|}
\hline Factor & $\begin{array}{l}\text { Relative } \\
\text { weight }\end{array}$ & $\begin{array}{l}\text { AISI } \\
1020 \\
\text { Score }\end{array}$ & $\begin{array}{l}\text { AISI } \\
1020 \\
\text { Value }\end{array}$ & $\begin{array}{l}\text { AISI } \\
1050 \\
\text { Score }\end{array}$ & $\begin{array}{l}\text { AISI } \\
1050 \\
\text { Value }\end{array}$ & $\begin{array}{l}\text { AISI } \\
304 \\
\text { Score }\end{array}$ & $\begin{array}{l}\text { AISI } \\
304 \\
\text { value }\end{array}$ & $\begin{array}{l}\text { AISI } \\
310 \\
\text { Score }\end{array}$ & $\begin{array}{l}\text { AISI } \\
310 \\
\text { Value }\end{array}$ \\
\hline $\begin{array}{l}\text { Mechanical } \\
\text { strength }\end{array}$ & $35 \%$ & 4 & 1,4 & 5 & 1,75 & 5 & 1,75 & 4 & 1,4 \\
\hline Density & $5 \%$ & 3 & 0,15 & 3 & 0,15 & 3 & 0,15 & 3 & 0,15 \\
\hline $\begin{array}{l}\text { Corrosion } \\
\text { resistance }\end{array}$ & $20 \%$ & 3 & 0,6 & 3 & 0,6 & 5 & 1 & 5 & 1 \\
\hline $\begin{array}{l}\text { Ease of } \\
\text { processing }\end{array}$ & $10 \%$ & 4 & 0,4 & 4 & 0,4 & 4 & 0,4 & 4 & 0,4 \\
\hline Cost & $30 \%$ & 5 & 1,5 & 5 & 1,5 & 3 & 0,9 & 3 & 0,9 \\
\hline Total & $\mathbf{1 0 0 \%}$ & & $\mathbf{4 , 0 5}$ & & $\mathbf{4 , 4}$ & & $\mathbf{4 , 2}$ & & $\mathbf{3}, \mathbf{8 5}$ \\
\hline
\end{tabular}

As can be seen from the table, an AISI 1050 steel was selected, but this steel does not have resistance to corrosion, in this way it is necessary to use an electrostatic powder coating treatment (coating usually used on bicycles and gym equipment) to improve corrosion resistance and increase durability

\subsection{Selection of Materials to be used in the Adjustable Parts of the Model}

The adjustable parts of the model must be resistant to corrosion without the need for coating paint, since the adjustment of the parts implies in most cases the 
sliding of the surfaces. In this way for the adjustable parts the selection will pass by the choice of a stainless steel (presented on the previous subchapter) or an aluminium alloy. In [16] It can be found a description of the aluminum alloys.
Table 3 shows a comparison between stainless steels and aluminium alloys following the method of comparison of table 2 .

Table 3. Comparison and selection of the materials for the structure of the model

\begin{tabular}{|l|c|c|l|l|l|l|l|l|l|}
\hline Factor & $\begin{array}{l}\text { Relative } \\
\text { weight }\end{array}$ & $\begin{array}{l}\text { AISI } \\
1020 \\
\text { Score }\end{array}$ & $\begin{array}{l}\text { AISI } \\
1020 \\
\text { Value }\end{array}$ & $\begin{array}{l}\text { AISI } \\
1050 \\
\text { Score }\end{array}$ & $\begin{array}{l}\text { AISI } \\
1050 \\
\text { Value }\end{array}$ & $\begin{array}{l}\text { AISI } \\
304 \\
\text { Score }\end{array}$ & $\begin{array}{l}\text { AISI } \\
304 \\
\text { value }\end{array}$ & $\begin{array}{l}\text { AISI } \\
310 \\
\text { Score }\end{array}$ & $\begin{array}{l}\text { AISI } \\
310 \\
\text { Value }\end{array}$ \\
\hline $\begin{array}{l}\text { Mechanical } \\
\text { strength }\end{array}$ & $35 \%$ & 5 & 1,75 & 4 & 1,4 & 3 & 1,05 & 3 & 1,05 \\
\hline Density & $5 \%$ & 3 & 0,15 & 3 & 0,15 & 5 & 0,25 & 5 & 0,25 \\
\hline $\begin{array}{l}\text { Corrosion } \\
\text { resistance }\end{array}$ & $20 \%$ & 5 & 1 & 5 & 1 & 5 & 1 & 5 & 1 \\
\hline $\begin{array}{l}\text { Ease of } \\
\text { processing }\end{array}$ & $10 \%$ & 4 & 0,4 & 4 & 0,4 & 3 & 0,3 & 3 & 0,3 \\
\hline Cost & $30 \%$ & 3 & 0,9 & 3 & 0,9 & 3 & 0,9 & 3 & 0,9 \\
\hline Total & $\mathbf{1 0 0 \%}$ & & $\mathbf{4 , 2}$ & & $\mathbf{3 , 8 5}$ & & $\mathbf{3 , 5}$ & & $\mathbf{3 , 5}$ \\
\hline
\end{tabular}

As can be seen from the table, an AISI 1050 steel was selected, but this steel does not have resistance to corrosion, in this way it is necessary to use an electrostatic powder coating treatment (coating usually used on bicycles and gym equipment) to improve corrosion resistance and increase durability

\subsection{Polymeric Materials}

For some components of the system (protections used in the modules) and for the bushes, polymeric materials will be used. Polymeric materials are widely used in the production of intermediate and finished products packaging. Nowadays most of the industries use polymeric materials in their products, in this way, it is common to find several polymeric materials in: transportation vehicles, medical equipment, scientific instruments, institutional products, furniture, electronics and clothing. The US Environmental Protection Agency states that in 2013, the United States generated about 14 million tons of plastics as containers and packaging, 12 million tons as appliances as durables-goods and nearly 7 million tons as non-durable goods such as plates and cups. There is a huge variety of polymeric materials, the most popular are: Polyethylene Terephthalate (PET), Polyvinyl Chloride (PVC), Polypropylene (PP) [17].

\subsection{Electrostatic Powder Coating}

Electrostatic painting is a treatment that allows to increase the resistance to corrosion and the durability of the parts. When a piece is painted with chemical powder, it receives an electric charge opposite the part, causing the powder to stick to the piece. After such a procedure, the piece is taken to an oven.
When the greenhouse heats up, the paint liquefies and then hardens, forming a film of high finish, uniformity and strength.

The most widely distributed powder with the biggest market share is the Epoxy/polyester powder. It has very good chemical resistance and excellent mechanical characteristics. Its gloss durability and its color appearance are, however, mediocre. Its fields of application are industrial equipment paneling, office furniture, machine tools, water heaters, radiators and shelving [18].

\section{Selection of Sensors}

In order to create the game, it is necessary to acquire some inputs: detection of the pedal velocity and detection of the position of the arms of the structure. To obtain this data, it will be necessary to use encoders and sensors to measure the position and velocity. In the following section there are presented the sensors that will be used for the detection of the pedal speed and the position of the arms of the structure.

\subsection{Detection of the Pedal Speed and Position of the Structure Arms}

For the detection of the pedal speed it will be used a Reed Switch sensor. The Reed sensors are used as highly effective speed sensors in low speed applications (up to 1000 RPM). A Reed sensor consists of a switch having two ferromagnetic blades contained within a hermetically sealed tubular glass housing. Generally, the gas present inside the glass is the nitrogen that serves to eliminate the presence of oxygen and to ensure that the contacts do not oxidize. Reed switches are usually activated by a permanent magnet or an electromagnet. 
This type of sensors allows solutions for detection of proximity, speed, flow, among others. In this way these sensors are very versatile possessing different utilities and forms [19].

For the detection of the position of the arms of the structure it will be used a rotary incremental encoder. The incremental encoders are of simpler manufacture when compared to the absolute encoder. This type of encoder generates only pulses and does not have a different combination for each position.
In this way, they are manufactured with a quantity of pulses per revolution [20]. The higher the number of pulses per revolution, the higher the encoder resolution. The disadvantage of this type of encoder is in the reading of its data, because as it operates by pulses, the reading of a certain positioning needs an initial reference, but they present a much lower cost when compared with the absolute encoders. Figure 8 shows the sensors that will be used.

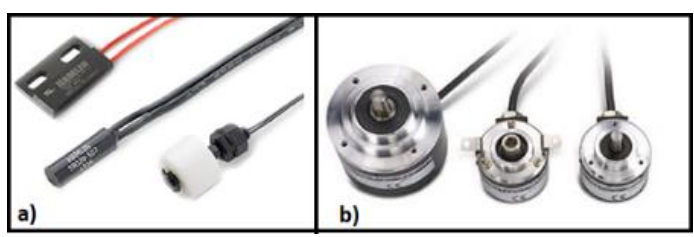

Figure 8: a) Reed Switch sensors [19]; b) Rotary encoders.

\section{Study of Exercises that can be Performed in the Proposed Model}

The main exercise performed in the use of a paramotor consists of a combined movement of glenhumeral abduction/adduction (abduction consists in moving the arm away from the median plane of the body while the adduction implies the approximation to this plane) with the humeroradial flexion/ extension movement (the humeroradial flexion consists of the approximation whereas the extension consists of the separation of the forearm from the shoulder, thus translating into a decrease and increase of the arm-forearm angle respectively). This movements implies the movement of the joints of the shoulder and elbow.

Figure 9 shows the execution of the movements described above.

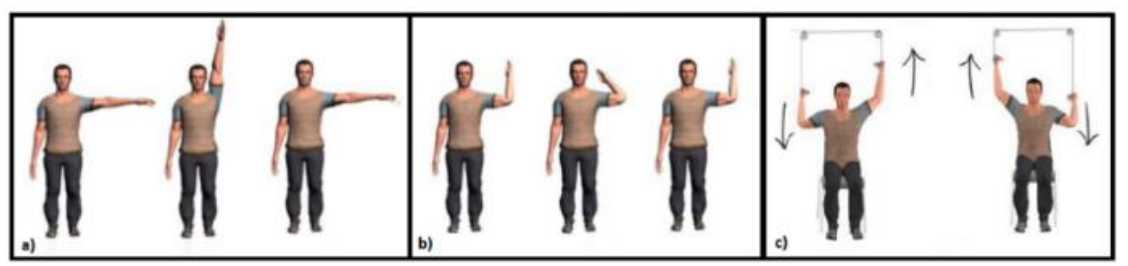

Figure 9: glen-humeral abduction/adduction; b) humeroradial flexion/extension;

c) combined movement of glen-humeral abduction/adduction with the humeroradial flexion/extension

In addition to the above described exercise, other exercises, such as glen-humeral flexion/extension, may be implemented, however the exercise that best represents the paramotor conduction is the combined exercise of glen-humeral abduction/adduction with the humeroradial flexion/extension [6]. During the execution of the arm exercises, the game also features a pedal that allows the user to train and strengthen the muscles of the legs, thus making physical activity and / or rehabilitation more enjoyable.

Figure 10 shows the use of the model. In this figure, it is possible to see the execution of the combined exercises of the arms and legs during the use of the game.

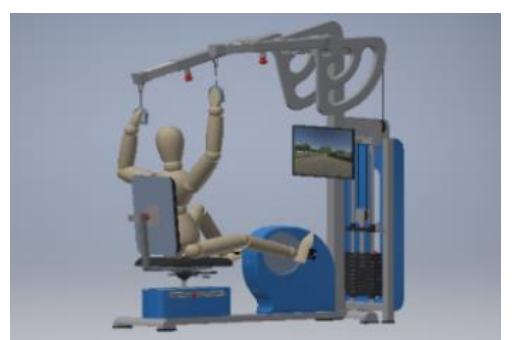

Figure 10: Execution of the game exercises in the model

\section{Development of the Game Scenario}

The chosen game consists of the simulation of a paramotor trip in which the character starts the game when he starts to pedal. 
During the game the user will have to go through different regions in which they will have to deviate of obstacles that appear while picking up the objects that give points if the exercise was preformed correctly.

One of the main goals will be to keep pedalling since the variation of the height will be simulated by the pedalling speed of the patient; in this case according to the speed of rotation of the pedal module, the patient will go up and down in the game scenario.

Figure 11 presents some of the different regions that can be found in the game.

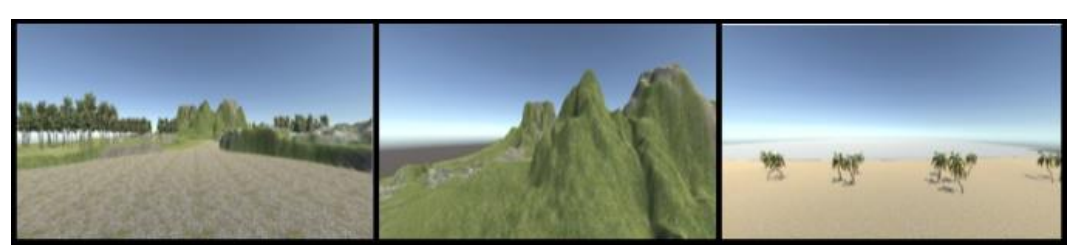

Figure 11: Some different regions found in the game

\section{Acknowledgements:}

The authors would like to express their acknowledgments to COMPETE: POCI-01-0145FEDER-007043 and FCT - Portuguese Foundation for science and technology within the Project Scope: UID/CEC/00319/2013.

\section{References}

[1] Abreu, M., \&Caldevilla, N.: Attitudes toward aging in portuguese nursing students. Procedia - Social and Behavioral Sciences. 171, 961-967 (2015).

[2] Zeng, N., Pope, Z., Eun, J., \&Gao, Z.: A systematic review of active video games on rehabilitative outcomes among older patients. Journal of Sport and Health Science. 6(1), 33-43 (2017).

[3] Martins, T., Carvalho, V., \& Soares, F.: Web Platform for Serious Games Management. Procedia - Procedia Computer Science. 64, 11151123 (2015).

[4] Pereira, L., Machado, J., Carvalho, V., Soares, F., \& Matos, D. Mechatronic system for the promotion of physical activity in people with motor limitations: first insights. Helix2018, June 27th 29th (2018).

[5] Pedraza-hueso, M., Martín-calzón, S., Díaz-pernas, F. J., \& Martínez-zarzuela, M.: Rehabilitation using Kinect-based games and Virtual Reality. Procedia - Procedia Computer Science. 75(Vare), 161-168 (2015).

[6] Martins, T.: Desenvolvimento de um jogo sério para fisioterapia, monitorização e motivação de pacientes com doenças neurológicas. Tese de Doutoramento, Universidade do Minho (2018); (in portuguese).

[7] Heller, B., Senior, T., \& Wheat, J.: The Smartfloor: a large area force-measuring floor for investigating dynamic balance and motivating exercise. Procedia Engineering. 226-231 (2014).

[8] Sensing. Future. (n.d.), physiosensing balance and pressure plate, https://www.physiosensing.net/, last accessed 2018/01/27.
[9] Motion Fitness. (n.d.), TWALL Targeted Training with a Fun https://www.motionfitness.com/, last accessed 2018/01/27.

[10] Sensing. Future. (n.d.), GymTop USB, https://www.sensingfuture-store.com/, last accessed 2018/01/27.

[11] Ltd, B. (n.d), http://bobo-balance.com, BALANCE BETTER, last accessed 2018/03/15.

[12] Pulsefitness. (n.d.), New ground breaking features on Trixter VR, http://www.trixter.net/, last accessed 2018/01/28.

[13] International stainless steel, http://www.worldstainless.org, last accessed 2018/04/10.

[14] Bramfitt, B. L., \& Benscoter, A. O.: Introduction to Steels and Cast Irons. Metallographer's Guide, ASM International. 2-8 (2002).

[15] Davis, J. R.: Introduction to stainless steels. ASM International, Material parks Ohio.37, 577 (2000).

[16] ASM International.: Aluminum and Aluminum Alloys. ASM International, Material parks Ohio. 117 (2015).

[17] Millholland, C. D.: A Guide to the World's Most Widely Used Plastics, https://www.thermofisher.com/blog, last acessed 2018/04/19.

[18] Surface finish equioment group. (n.d.), The electrostatic powder coating, http://www.sfeg.co.uk/, last accessed 2018/04/20.

[19] LittelFuse. (n.d.), PRODUCT CATALOG \& DESIGN GUIDE (SENSORS), http://www.littelfuse.com, last accessed 2018/04/20.

[20] CHI HUA Fitness co. (n.d.), "EDDY CURRENT BREAK (ECB), http://www.chihua.com.tw/en/, last accessed 2018/04/30. 